\title{
Transplantation of Neural Precursor Cells in the Treatment of Parkinson's Disease: An Efficacy and Safety Analysis
}

\author{
Leng LIGE, Tian ZENGMIN \\ Institute of Neurosurgery, The PLA Navy General Hospital, Beijing, China
}

\section{ABSTRACT}

AIM: The aim of this study was to evaluate the clinical safety, feasibility and efficacy of transplantation of neural precursor cells (NPCs) in the treatment for Parkinson's disease (PD).

MATERIAL and METHODS: Twenty-one patients, aged 42-79 years (median age 57.33 years), participated in the study. A total of $3 \times 107 \mathrm{NPCs}$ in $0.25 \mathrm{ml}$ were deposited unilaterally into the striatum. To access the effectiveness of first transplantation surgery, comparisons between the resulting pre-first surgery evaluation and pre-second surgery evaluation were made with repeatedmeasures analysis of variance. Unified Parkinson's Disease Rating Scale (UPDRS), Hoehn-Yahr, PDQ-39 and Schwab-England Scores were used to evaluate the Parkinson patients' neurofunctions. Four aspects were used to assess the possible side effects of transplantation: a) tumor formation, b) immune rejection and use of immunosuppressant, c) graft induced complication and d) delivery related side effects.

RESULTS: This study demonstrated that the symptoms of PD patients were statistically improved after transplantation $(P<0.01)$. There were no obvious side effects of transplantation.

CONCLUSION: Transplantation of neural precursor cells may be a valid and safe treatment method for Parkinson's Disease.

KEYWORDS: Parkinson's disease, Transplantation, NPCs, Safety, Efficacy

\section{INTRODUCTION}

Parkinson's disease (PD), also called parkinsonism, is the most common central nervous system degenerative disease secondary to dopaminergic neuron loss in the substantia nigra pars compacta (SNc), decrease in the synthesis of dopamine and excitation of acetylcholine (24). Most evident symptoms are movement-related, including movement disorders, tremor and rigidity.

Gradually, thinking and behavioral problems may arise, with dementia commonly occurring in the last phases of the disease, whereas depression is the most common psychiatric symptom.

Dementia and depression will heavily influence the quality of patient lives. Other symptoms include sensory, emotional and psychiatric problems. Recent studies demonstrated that transplantation of all kinds of human stem cells into patients with PD could help replacing endogenous degenerating dopamine (DA) neurons and ameliorate the clinical symptoms of $\operatorname{PD}(2,6,7)$.

Recent studies have revealed the successful reversal of parkinsonian symptoms in monkeys, rats, and patients with PD after transplantation of different kinds of stem cells $(18,22$, $23,24)$. However, the safety and valuation of transplantation of neural precursor cells (NPCs) remains controversial.

A boy with ataxia telangiectasia (AT) was treated not only with intracerebellar but intrathecal injection of human fetal NPCs. Four years after the transplantation he came with a multifocal brain tumor. Molecular and cytogenetic genetics detections 
showed that the tissue of the tumor was not of host origin, suggesting it was derived from the transplanted neural precusor cells. Those microsatellite and HLA detections also demonstrated that the tumor was derived from at least two donors (1). People worried that there were potential dangers associated with stem cell transplantation, such as malignant transformation $(12,13)$ and tumor formation as mentioned above.

The objective of this trial was to evaluate the clinical safety and effectiveness of transplantation of neural precursor cells in the treatment for PD.

\section{MATERIAL and METHODS}

\section{Patients Selection}

Twenty-one patients, aged 42-79 years (median age 57.33 years), were eligible to participate in the study. All these patients had undergone transplantation surgery twice and the period between the two surgeries was 7-57 months. The patients demonstrated bilateral but asymmetric PD clinical features. Criteria for exclusion from this study included: 1. Secondary Parkinsonism, 2. Parkinson's plus syndromes, 3. Previous brain surgery, epilepsy, severe cognitive disorder or depression, cerebrovascular disease, evidence on magnetic resonance imaging (MRI) of other neurologic disorder, 4. Hallucinations or delusions during levodopa therapy 5. Any medical contraindication to surgery. There were no medical contraindications for surgery in these patients by preoperative studies and examinations.

All patients were informed about this clinical study and signed consents of the patients were received for the operations and the relevant procedures. The protocol and a consent form describing in detail the potential risks and benefits of the study were discussed and approved by the Institutional Review Boards of the Navy General Hospital and a Performance and Safety Monitoring Board appointed by the National Institutes of Health.

Every patient and relative were informed in detail and signed the informed consent forms. Comparisons between the resulting pre-first surgery evaluation and pre-second surgery evaluation were made with repeated-measures analysis of variance. At the second hospitalization period, we could minute, confirmable exam the safety of the first transplantation surgery.

NPCs were provided by the Center for Stem Cell Research, Navy General Hospital. Embryonal Stem Cells (ESCs) were differentiated into NPCs and dopaminergic neurons. The aborted fetal samples (10-20 weeks) were acquired from Beijing Maternity Hospital with the mother's consent. All mothers had no history of genetic disease and infectious disease. Permission to use human tissue was granted by the Ethical Committee of Peking University Health Science Center (Ethical committee approval number 154).

After the cell layers were dissected, they were directly put into sterile phosphate-buffered saline (PBS), and cut into small pieces of $1 \mathrm{~mm}^{3}$. The cell suspension was then triturated with glass pipettes gently, passed through a 70-um strainer, and maintained in Dulbecco modified Eagle's medium/ nutrient mixture F12 (DMEM/F12; Gibco BRL, Rockville, MD) supplemented with $10 \%$ fetal bovine serum (FBS; Hyclone, Hyclone Laboratories, Logan, UT, USA), bFGF (20 ng/mL; Gibco BRL), EGF (20 ng/mL; Gibco BRL) and LIF (10 ng/mL; Chemicon, Chemicon International, Inc., Temecula, CA, USA), respectively (24). Seven-ten days later, a few small adherent clones were appeared. These clones were isolated and cultured to obtain NPCs. The medium was replaced every 3-5 days. Passage was carried out when cells were observed to grow among $95 \%$ confluent. Cells were trypsinized with $0.25 \%$ trypsin (Gibco BRL) and were passaged at 1:3 ratios. Cells from passage 5-10 were used for the following experiments. Cells induced with PACAP and dbCAMP-RA-bFGF cocktail were harvested at 2 days (24).

\section{Method of Transplantation}

During the surgical procedure, patients were put in a Fisher stereotactic frame after accepting local anesthesia, and the putamen was visualized on high-field-strength MRI (1.5T) using a fast spin-echo sequence. The target site for the injection was located in the striatum. Then, the patients were delivered to the operating room. After another local anesthesia, a burr hole was drilled in the calvarium, $5 \mathrm{~mm}$ anterior to the coronal suture and $25 \mathrm{~mm}$ side from midline. A total of $3 \times 10^{7} \mathrm{NPCs}$ in $0.25 \mathrm{ml}$ were injected unilaterally in the striatum in one trace, from ventral to dorsal (24). After the final injection, a 5-min equilibration was required to allow the injected cell suspensions and stabilization to avoid these cells withdrawal along the needle tract when the needle is removed from the brain. The withdrawal of injected needle was gradual and steady with frequent brief pauses to avoid any vacuum effect. After injection, patients' language and limbs movement abilities were tested. The last process was suturing the incision and labeling a sterilized dressing (24).

\section{Efficacy}

To access the effectiveness of first transplantation surgery, comparisons between the resulting pre-first surgery evaluation and pre-second surgery evaluation were made with repeatedmeasures analysis of variance. Unified Parkinson's Disease Rating Scale (UPDRS), Hoehn-Yahr, PDQ-39 and SchwabEngland Scores were used to evaluate those Parkinson patients' neurofunctions. These four scores were not only motor status scores, but scores which accessed on neural function and mentality of the patients.

\section{Safety}

We assess the possible side effects of transplantation from four aspects: tumor formation, immune rejection and use of immunosuppressant, graft induced side effects and delivery related side effects. We used MRI to observe if there were brain tumors when we followed up the patients.

\section{Data Analysis}

Statistical analysis was carried out using SPSS 20.0 software. The results of baseline evaluations and the postoperative evaluation results were compared with repeated-measures 
analysis of variance (24). $P$ values at $<0.01$ were regarded as statistically significant.

\section{RESULTS}

The characteristics of each patient are shown in Table I. The length between the two surgeries was 7-57 months, where six were $<12$ months, seven were 12 36 months, and eight were $\geq 36$ months. The symptoms of PD patients were improved (most on the contralateral side to the implanted striatum) up to 57 months after transplantation (Table II, Figures 1-4).

\section{Safety}

1. Tumor formation: We used MRI during the second hospitalization period to observe the safety of the first transplantation surgery. We could clearly see that there was no tumor formation on postoperative MRI compared to the MRI before cell transplantation (Figure 5). MRI of the patients during the second hospitalization period is shown in Table III.

2. Immune rejection and use of immunosuppressant: No immunosuppressive drug was used in this group of patients. There was no severe immune rejection observed in our study. Local blood-brain barrier was not damaged, temporality edema of brain tissue was not occured, small blood vessels were not injured, no other local tissue inflammatory responses were observed in this study.

3. Graft-induced side effects: None of the patients had any complication related to the transplantation, including any dyskinesia or aphasia.

4. Delivery-related side effects: Following the operation, patients were transferred and observed in the intensive care

Table I: Patient Characteristics

\begin{tabular}{|c|c|c|c|c|}
\hline $\begin{array}{l}\text { Inpatient } \\
\text { No. }\end{array}$ & $\begin{array}{c}\text { Age } \\
\text { (years) }\end{array}$ & Gender & $\begin{array}{l}\text { Length between two } \\
\text { hospitalization (months) }\end{array}$ & Drug(mg) \\
\hline \multicolumn{5}{|c|}{ Length between two surgeries (<12 months) } \\
\hline 305193 & 67 & Male & 7 & Madopar 500 \\
\hline 306577 & 43 & Male & 7 & Madopar 750 \\
\hline 322758 & 55 & Male & 9 & Madopar 750 \\
\hline 311488 & 57 & Male & 10 & Madopar 500 Antanum 8 \\
\hline 305853 & 66 & Male & 11 & Madopar 1250 Carbidopa 50 levedopa 250 \\
\hline 309534 & 52 & Female & 11 & Madopar 750 Carbidopa 50 levedopa 250 \\
\hline \multicolumn{5}{|c|}{ Length between two surgeries (12 36 months) } \\
\hline 329463 & 55 & Female & 12 & Madopar 750 \\
\hline 310535 & 50 & Female & 15 & Carbidopa 100 levedopa 250 \\
\hline 309899 & 67 & Male & 15 & Madopar 1000 \\
\hline 312267 & 61 & Male & 22 & Carbidopa 50 levedopa 250 \\
\hline 286531 & 66 & Male & 26 & Madopar 750 Antanum 8 \\
\hline 312366 & 42 & Male & 29 & Madopar 750 \\
\hline 306536 & 50 & Male & 30 & Madopar 750 \\
\hline \multicolumn{5}{|c|}{ Length between two surgeries ( $\geq 36$ months) } \\
\hline 297846 & 79 & Male & 36 & Madopar 750 Antanum 8 \\
\hline 252217 & 54 & Female & 36 & Madopar 1000 \\
\hline 266679 & 55 & Female & 36 & Madopar 750 \\
\hline 313064 & 68 & Male & 36 & Madopar 750 \\
\hline 314776 & 62 & Female & 37 & Madopar 750 \\
\hline 310631 & 52 & Male & 41 & Madopar 750 \\
\hline 312667 & 54 & Male & 49 & Madopar 750 Piribedil 200 \\
\hline 305653 & 49 & Male & 57 & Madopar750 \\
\hline
\end{tabular}


Table II: Four Different Scores in Patients Before and After Cell Implantation

\begin{tabular}{ccc}
\hline Scores & Pre-first surgery & $\begin{array}{c}\text { Pre-second } \\
\text { surgery }\end{array}$ \\
\hline UPDRS & $80.71 \pm 15.48$ & $72.76 \pm 13.31$ \\
\hline MBM & $6.43 \pm 1.40$ & $5.95 \pm 1.28$ \\
\hline ADL & $28.52 \pm 7.96$ & $23.62 \pm 7.55$ \\
\hline Motor & $35.52 \pm 6.51$ & $33.48 \pm 5.26$ \\
\hline $\begin{array}{c}\text { Complication } \\
\text { of drug }\end{array}$ & $10.19 \pm 1.59$ & $9.71 \pm 1.22$ \\
\hline Hoehn-Yahr & $3.71 \pm 0.94$ & $2.86 \pm 1.05$ \\
\hline PDQ-39 & $110.62 \pm 17.62$ & $104.90 \pm 17.60$ \\
\hline Schwab-England & $37.14 \pm 13.47$ & $52.38 \pm 14.11$ \\
\hline
\end{tabular}

$P<0.01$.

Table III: MRI No. of the Patients during the Second Hospitalization Period

\begin{tabular}{|c|c|}
\hline Inpatient No. & MRI No. \\
\hline 329463 & MRI24589 \\
\hline 310535 & MRI11237 \\
\hline 322758 & MR16527 \\
\hline 297846 & MRI09580 \\
\hline 309534 & MRI17346 \\
\hline 314776 & MRI35482 \\
\hline 313064 & MRI04180 \\
\hline 312667 & MRI25973 \\
\hline 312366 & MRI29476 \\
\hline 312267 & MRI03643 \\
\hline 311488 & MRI18264 \\
\hline 310631 & MRI21435 \\
\hline 305193 & MRI28215 \\
\hline 252217 & MRI28752 \\
\hline 266679 & MRI28476 \\
\hline 309899 & MRI27463 \\
\hline 306577 & MRI18463 \\
\hline 306536 & MRI18668 \\
\hline 305853 & MRI05648 \\
\hline 305653 & MRI47461 \\
\hline 286531 & MRI 38724 \\
\hline
\end{tabular}

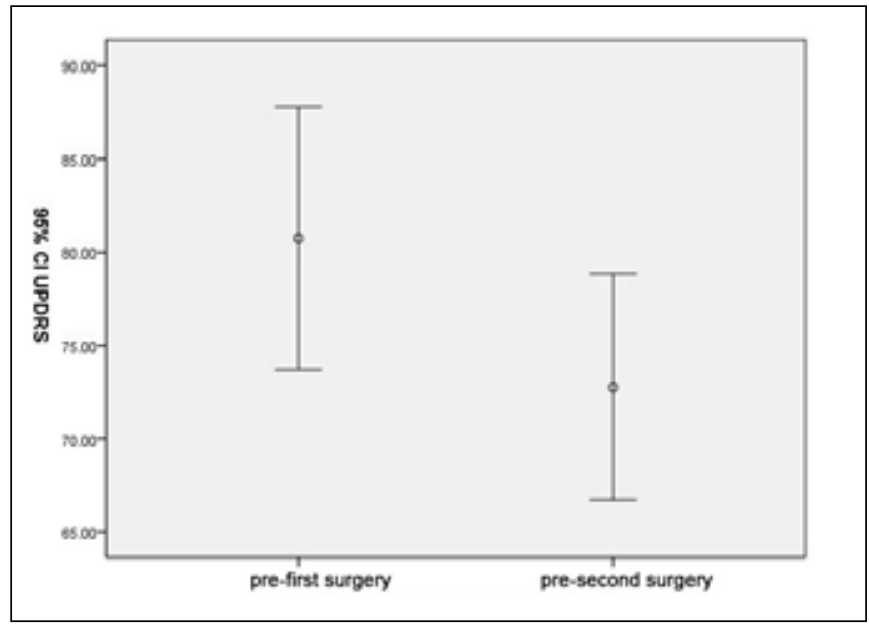

Figure 1: Unified Parkinson's disease rating scale (UPDRS) scores in patients before and after cell implantation.

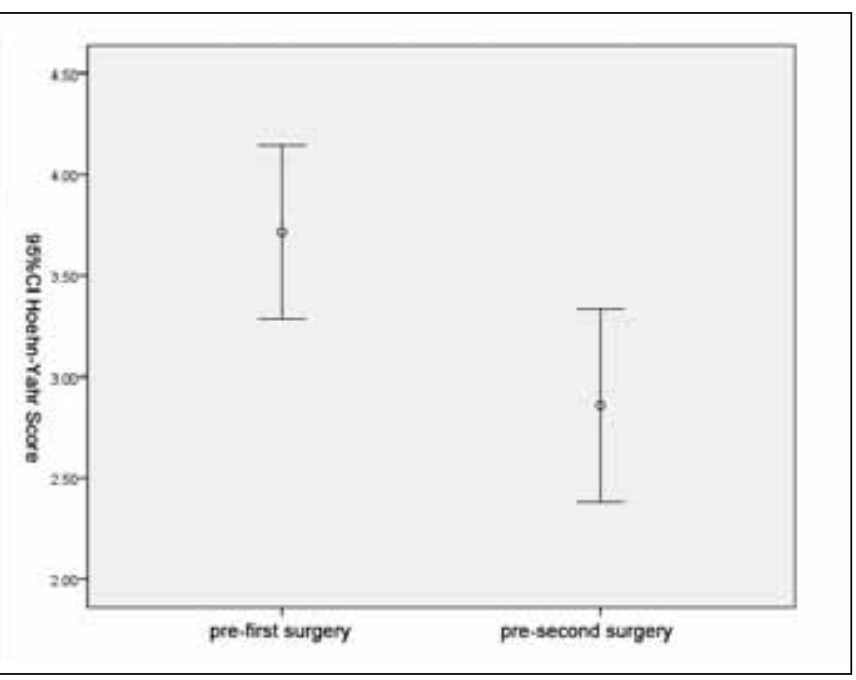

Figure 2: Heohn-Yahr scores in patients before and after cell implantation.

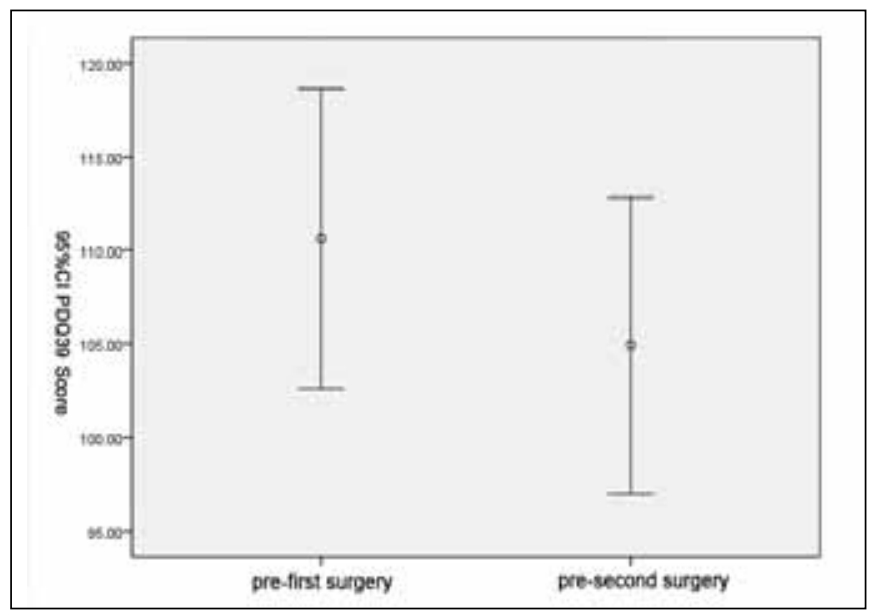

Figure 3: PDQ-39 scores in patients before and after cell implantation. 


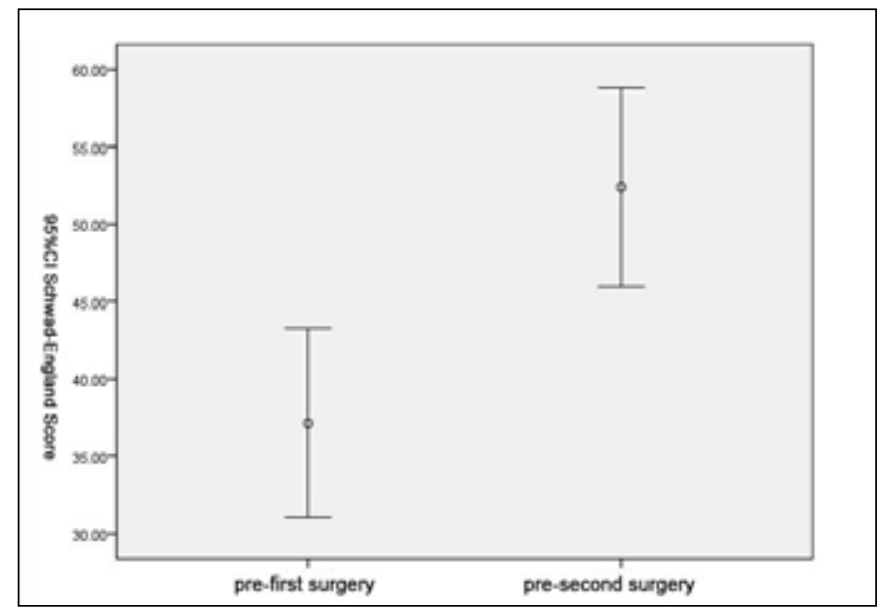

Figure 4: Schwab-England scores in patients before and after cell implantation.

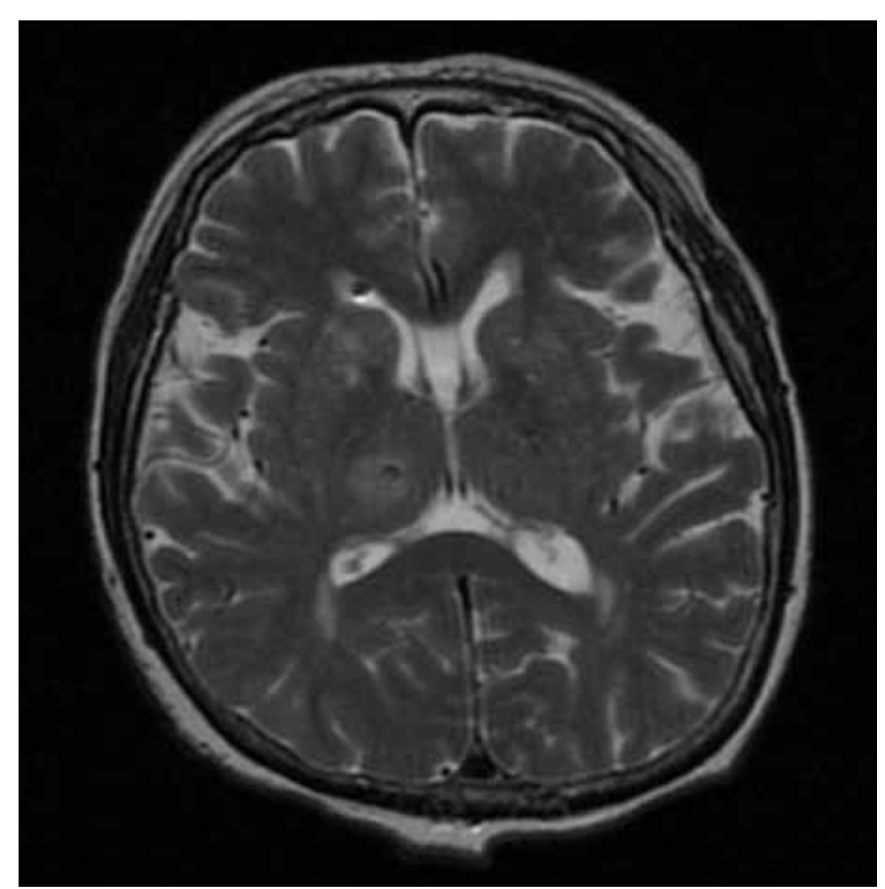

Figure 5: Axial image of MRI of one patient during the second hospitalization period.

unit overnight and then sent to a conventional ward next morning. All patients were discharged from hospital within 7 days. No one had severe hemorrhage or infection.

\section{DISCUSSION}

PD, which can be idiopathic or primary, is a degenerative disorder of the central nervous system. The motor symptoms of PD result from the death and decline of dopaminegenerating neurons in the substantia nigra, the cause of the formation of this disease is unknown and in dispute. PD is one of the most common diseases in the elderly, with an incidence that peaks after the $5^{\text {th }}$ decade $(9,10,19,21)$. However, the safety of the precursor cell implantation was not clear and argumentative. Injection of pluripotent ESC or precursor cells in rodents often resulted in the formation of teratomas or teratocarcinomas $(8,16)$, although these stem cells' ability to differentiate into tumor has been greatly reduced when they are predifferentiated in vitro before transplantation process. $(3,4,15)$. More importantly, ESCs seem much easier to form tumors when transplanted into the same species from which they were derived (8). Therefore it has been noted that the absence of tumors after implantation of human stem cells into rodents does not exclude their occurrence in the human brain. Lately, transplantation human ESC-derived dopaminergic cells enriched by telomerase-immortalized astrocytes resulted in undifferentiated proliferation suggesting that there was a potential to form a tumor when it transplanted to rodents (17). Stem cells have been used to treat many incurable and severe diseases, including Parkinson's disease, trauma and hematencephalon.

All of the patients in our study had inpatient treatment twice, including the first cell transplantation surgery. So not only could we fully assess the efficacy of first surgery, but also fully assessed the safety of the first surgery. After the patients were admitted to the hospital the second time, we conducted a MRI examination to access the safety of cell transplantation surgery. We also conducted routine examinations for the patients, to judge the safety of the first surgery with a more comprehensive observation. We have all 21 patients' postoperative follow-up MRI scans. Some patients had bilateral thalamic surgery. Eight of these patients had a positron emission tomography (PET)-Computed tomography (CT) scan. Six patients demonstrated an increased uptake of radionuclide dopamine transporter (DAT) in the putamen of the implant side 6 months after transplantation. One patient underwent PETCT scan at 12 months after implantation, and no important changes in the implant side were detected. One patient underwent PET scan at 24 months after transplantation, whose visualized PET image showed that the putaminal fluorodopa uptake was higher in the non-graft side than in the other side.

All patients tolerated the surgical procedure well, without any major side effect or complication. No bleeding or edema was found in the brain after the transplantation. No mass or abnormal growth at the transplant sites was found after surgery or in the follow-up period. Whether immunosuppressant agents should be used in PD patient treatment by implanting human retinal pigment epithelial (hRPE) cells is still controversial. In animal studies, cellular immune response aiming at bone marrow stromal cells in a rat model of Parkinson's deficit was found (5). These cells, when injected into the striatum of rats, aroused a significant immune response which was not enough to clear all the cells after transplantation. Recent studies have shown that when transplanting precursor cells carried by gelatin microcarriers, these cells could survive for a prolonged time with the lack of immunosuppressive therapy (20). However, increasing evidence pointed out that the implant process could induce damage in the local blood-brain barrier, small blood vessel injuries, and other local inflammatory responses $(11,14)$. In our study, no immunosuppressive drug was used in treatment, and there were no noticeable inflammatory responses after the operation, showing that NPCs had low immunogenicity in treating PD patients. 


\section{CONCLUSION}

Transplantation of neural precursor cells in the treatment for Parkinson's Disease could be valid and safe.

\section{- REFERENCES}

1. Amariglio N, Hirshberg $A$, Scheithauer BW, Cohen $\mathrm{Y}$, Loewenthal R, Trakhtenbrot L, Paz N, Koren-Michowitz M,Waldman D, Leider-Trejo L, Toren A, Constantini S, Rechavi G: Donor-derived brain tumor following neural stem cell transplantation in an ataxia telangiectasia patient. PLoS Med 6:e1000029, 2009

2. Annett LE: Functional studies of neural grafts in parkinsonian primates. In: Dunnett SB, Bjorklund A (eds), Functional Neural Transplantation. New York: Raven Press, 1994:71-102

3. Arnhold S, Lenartz D, Kruttwig K, Klinz FJ, Kolossov E: Differentiation of green fluorescent protein-labeled embryonic stem cell-derived neural precursor cells into Thy-1-positive neurons and glia after transplantation into adult rat striatum. $J$ Neurosurg 93: 1026-1032, 2000

4. Brustle O, Jones KN, Learish RD, Karram K, Choudhary K: Embryonic stem cell-derived glial precursors: A source of myelinating transplants. Science 285:754-756, 1999

5. Camp DM, Loeffler DA, Farrah DM, Borneman JN, LeWitt PA: Cellular immune response to intrastriatally implanted allogeneic bone marrow stromal cells in a rat model of Parkinson's disease. J Neuroinflammation 6:17, 2009

6. Defer GL, Geny C, Ricolfi F: Long-term outcome of unilaterally transplanted parkinsonian patients. I. Clinical approach. Brain 119:41-50, 1996

7. Duan $W M$, Widner $H$, Brundin $P$, Brundin $P$ : Sequential intrastriatal grafting of allogeneic embryonic dopaminerich neuronal tissue in adult rats; will the second graft be rejected? Neuroscience 57: 261-274, 1993

8. Erdo F, Buhrle C, Blunk J, Hoehn M, Xia Y: Host-dependent tumorigenesis of embryonic stem cell transplantation in experimental stroke. J Cereb Blood Flow Metab 23:780-785, 2003

9. Finneman SC, Boulan E: Macrophage and retinal pigment epithelium phagocytosis apoptotic cells and photo receptors compete for AV B3 and AV B5 integrins, and protein kinase C regulates AV B5 binding and cytoskeletal linkage. J Exp Med 190:861-874, 1990

10. Freed CR, Greene PE, Breeze RE: Transplantation of embryonic dopamine neurons for severe Parkinson's disease. N Engl J Med 344:710-719, 2001
11. Jeanne AP: Prospect of cell therapy for Parkinson's disease. Anat Cell Biol 44: 256-264, 2011

12. Lindvall $O$, Kokaia $Z$ : Stem cells for the treatment of neurological disorders. Nature 441: 1094-1096, 2006

13. Lindvall O, Kokaia Z, Martinez-Serrano A: Stem cell therapy for human neurodegenerative disorders-how to make it work. Nat Med 10 Suppl: S42-50, 2004

14. Politis $M$ : Dyskinesias after neural transplantation in Parkinson's disease: What do we know and what is next? BMC Med 8:80, 2010

15. Reubinoff BE, Itsykson P, Turetsky T, Pera MF, Reinhartz E: Neural progenitors from human embryonic stem cells. Nat Biotechnol 19:1134-1140, 2001

16. Reubinoff BE, Pera MF, Fong CY, Trounson A, Bongso A: Embryonic stem cell lines from human blastocysts: Somatic differentiation in vitro. Nat Biotechnol 18: 399-404, 2000

17. Roy NS, Cleren C, Singh SK, Yang L, Beal MF: Functional engraftment of human ES cell-derived dopaminergic neurons enriched by coculture with telomerase-immortalized midbrain astrocytes. Nat Med 12:1259-1268, 2006

18. Stover NP, Roy AE: Intrastriatal implantation of human retinal pigment epithelial cells attached to microcarriers in advanced Parkinson's disease. Arch Neuro 162:1833-1837, 2005

19. Subramanian T, Marchionini D, Potter EM. Cornfeldt M: Striatal xenotransplantation of human retinal pigment epithelial cells attached to microcarriers in hemiparkinsonian rats ameliorates behavioural deficits without provoking a host immune response. Cell Transplant 11: 207-214, 2002

20. Tezel TH, Del Priore VL: Reattachment to a substrate prevents apoptosis of human retinal pigment epithelium. Graefes Arch Clin Exp Ophthalmol 235: 41-47, 1997

21. Wang R, Zhang J, Guo Z: In-vivo PET imaging of implanted human retinal pigment epithelium cells in a Parkinson's disease rat model. Nucl Med Commun 5:455-461, 2008

22. Watts RL, Raiser CD, Stover NP: Stereotaxic intrastriatal implantation of retinal pigment epithelial cells attached to microcarriers in advanced Parkinson's disease (PD) patients: A pilot study. Neurology 58: 241-244, 2005

23. Watts RL, Raiser CD, Stover NP: Stereotaxic intrastriatal implantation of human retinal pigment epithelial (hRPE) cells attached to gelatin microcarriers: A potential new cell therapy for Parkinson's disease. J Neural Transm 65: 215-227, 2005

24. Yin F, Tian ZM, Liu S, Zhao QJ, Wang RM, Shen L, Wieman $J$, Yan Y: Transplantation of human retinal pigment epithelium cells in the treatment for Parkinson's disease. CNS Neurosci Ther 18(12):1012-1020, 2012 